\title{
New developments in mode-water research: an introduction
}

\author{
Shang-Ping Xie $\cdot$ Atsushi Kubokawa \\ Fumiaki Kobashi $\cdot$ Humio Mitsudera
}

Published online: 4 December 2011

(C) The Oceanographic Society of Japan and Springer 2011

Two landmark papers appeared in 1969, laying the foundation for this special section in Journal of Oceanography. Masuzawa (1969) coined the term "subtropical mode water" (STMW) in the North Pacific, characterizing it as a thick, vertically uniform layer of $\sigma_{\theta} 25.2-25.6$ that forms a distinct mode in water volume censuses as a function of temperature, salinity or density. By carefully studying historical hydrographic observations, Uda and Hasunuma (1969) discovered an eastward subtropical countercurrent (STCC) in the southern subtropical gyre where the Sverdrup theory predicts a broad westward current. This countercurrent is peculiar in its direction against both the prevailing

\section{S.-P. Xie $(\bowtie)$}

International Pacific Research Center and Department of Meteorology, SOEST, University of Hawaii at Manoa, Honolulu, HI 96822, USA

e-mail: xie@hawaii.edu

\section{S.-P. Xie}

Physical Oceanography Laboratory, Ocean University of China, Qingdao 266100, China

\author{
A. Kubokawa \\ Faculty of Environmental Earth Science, Hokkaido University, \\ Sapporo 060-0810, Japan \\ F. Kobashi \\ Faculty of Marine Technology, Tokyo University of Marine \\ Science and Technology, Tokyo 135-8533, Japan \\ F. Kobashi \\ Research Institute for Global Change, Japan Agency \\ for Marine-Earth Science and Technology, \\ Yokosuka 237-0061, Japan \\ H. Mitsudera \\ Institute of Low Temperature Science, Hokkaido University, \\ Sapporo 060-0819, Japan
}

northeast trade winds and the westward current underneath. Uda and Hasunuma noted in passing that the STMW resides north of the STCC, splitting the thermocline into a northward-shoaling upper branch and a downward-sloping lower thermocline. Since then, studies of mode water and STCC went their separate ways. The STMW is a favorite subject for water-mass analysts, with other mode waters found in the 1990s in the central and eastern North Pacific. The strong deviation of STCC from the barotropic Sverdrup streamfunction, on the other hand, captured the imagination of dynamists, who proposed a flurry of theories that attempt to explain this peculiar current.

A self-consistent theory of STCC had to wait for 30 years, identifying none other than mode waters as the culprit. As often happens in history, seemingly distinct phenomena-mode water and STCC in this case-turn out to be closely related from a fresh perspective under the light of new theories. Based on a ventilated thermocline model, Kubokawa (1999) showed that mode waters of different densities, formed in the deep winter mixed layer around the Kuroshio Extension east of Japan, will cross their paths on their way south in the subtropical gyre, stack up in the vertical, and shoal the upper thermocline, creating a surface-intensified STCC on the south flank of the modewater pool. Subsequent observational and modeling studies lend support for this theory of STCC. Thus, mode waters are far more than just thick water masses moving around passively in the subtropical gyre but assume the role of a dynamical agent that causes surface currents to deviate substantially from the Sverdrup dynamics. In retrospect, the dynamical effect of mode water may not be too surprising given that mode waters are characterized by their low potential vorticity, and that potential vorticity is a dynamical tracer conservative following a parcel's trajectory on an isopycnal. 
Important technological advances for the past decade enabled impressive progress in the description and understanding of mode-water formation, variability, and its dynamical and climatic effects. Argo profiling floats, in synergy with satellite altimetry, revealed the important role played by meso-scale eddies in mode-water formation, with STMW preferentially formed in anticyclonic eddies/ meanders of the Kuroshio Extension. High-resolution ocean general circulation models (GCMs) that resolve meso-scale eddies offer a useful tool to study variability and interaction of jets, eddies, and mode waters. Results from satellite observations and coupled ocean-atmosphere GCMs showed that STCC, its variability and change leave visible imprints on, and induce feedback from, the atmosphere.

A symposium entitled "New Developments of ModeWater Research: Dynamic and Climatic Effects" was convened on the Shinagawa campus of the Tokyo University of Marine Science and Technology on 26 March 2010 as part of the Spring Meeting of the Oceanographic Society of Japan. Twelve talks were presented to an enthusiastic audience of about 100 people. A consensus was reached to showcase recent progress in mode-water research in a compendium of papers in a scientific journal. This special section of 10 papers in Journal of Oceanography is the result. It includes both papers presented at the symposium and those submitted in response to a call for special-section contributions. They cover a wide range of topics from the formation, circulation and variability of mode waters, their dynamic effect on surface current, and climate impact.

The special section features three review papers. Oka and Qiu (2012) showcase progress in studying the formation and circulation of mode waters based on recent observations. Kobashi and Kubokawa (2012) give a historical account of the developments in dynamical understanding of STCC, and review recent results on dynamic and climatic effects of mode-water ventilation. Masuzawa (1969) drew an analogy between the North Pacific STMW and the $18^{\circ} \mathrm{C}$ water of the North Atlantic. Joyce (2012) highlights new perspectives of the North Atlantic $18^{\circ} \mathrm{C}$ water gained from the field experiment Clivar mode water dynamics experiment" (CLIMODE).

Seven original research articles in the special section present the latest research into mode water and its dynamic and climatic effects. A pair examines mode water formation processes: in a non-eddy resolving ocean GCM, Nishikawa and Kubokawa (2012) study the formation of a mixed layer depth front in winter over the northwest subtropical gyre and its role in mode water subduction; the analysis of Argo observations by Kouketsu et al. (2012) reveals a strong modulation of the winter mixed layer by eddies, with large depths observed inside anti-cyclonic eddies. Toyama and
Suga (2012) examines the influence of mode waters on the central water, a water mass in the main pycnocline characterized by a constant density ratio on $\mathrm{T}-\mathrm{S}$ diagrams.

Two papers examine mode-water effects on interannual variability in eastward surface jets based on an eddyresolving ocean GCM: Sasaki et al. (2012) suggest that the anomalous southward intrusion of low potential-vorticity water strengthens the Hawaii Lee Countercurrent on interannual timescales, a result they support with Argo observations; Nonaka et al. (2012) show that mode-water ventilation is the dominant mechanism for STCC variability on interdecadal timescales and remains in a significant role on interannual timescales. The observational analysis by Kobashi and Xie (2012) confirms that local wind is important for STCC variability on interannual timescales, and suggests an interaction between local wind and STCC in late spring. This revives the wind-driven idea of Yoshida and Kidokoro (1967), not for the mean STCC but for seasonal and interannual variations. Based on a global warming simulation, $\mathrm{Xu}$ et al. (2012) show that mode waters weaken their low potential-vorticity characteristic as ocean stratification increases and the winter mixed layer shallows along the Kuroshio Extension, reducing the Kuroshio Extension's influence on the STCC.

Papers in the special section point to new directions for mode-water research. How do mode waters vary on decadal and longer timescales, and how will they change in response to global warming? What causes mode water variability, and how does it affect the surface circulation and climate of the central and southern subtropical gyre? What are the roles of meso-scale eddies in the formation and dissipation of mode waters, and in their variability and change? We hope that this special section will serve as a sign post in our endeavor to answer these challenging questions.

Acknowledgments We, the editorial team for this special section (A.K., the guest editor in chief), wish to thank all the reviewers for their time and effort essential to maintain the scientific rigor of this special section, T. Saino and T. Hibiya, Chief Editors of the journal, for their editorial guidance. This work is supported by the Japan Agency for Marine-Earth Science and Technology, the National Basic Research Program of China (3012CB955600), the US National Science Foundation (0854365), and Grants-in-Aid for Scientific Research of the Ministry of Education, Culture, Sports, Science and Technology, Japan (22106007, 23340139).

\section{References}

Joyce TM (2012) New perspectives on eighteen-degree water formation in the North Atlantic. J Oceanogr 68. doi:10.1007/ s10872-011-0029-0

Kobashi F, Kubokawa A (2012) Review on North Pacific Subtropical Countercurrents and Subtropical Fronts: role of mode waters in ocean circulation and climate. J Oceanogr 68. doi:10.1007/ s10872-011-0083-7 
Kobashi F, Xie SP (2012) Interannual variability of the North Pacific Subtropical Countercurrent: role of local ocean-atmosphere interaction. J Oceanogr 68. doi:10.1007/s10872-011-0048-X

Kouketsu S, Tomita H, Oka E, Hosoda S, Kobayashi T, Sato K (2012) The role of meso-scale eddies in mixed layer deepening and mode water formation in the western North Pacific. J Oceanogr 68. doi:10.1007/s10872-011-0049-9

Kubokawa A (1999) Ventilated thermocline strongly affected by a deep mixed layer: a theory for subtropical countercurrent. J Phys Oceanogr 29:1314-1333

Masuzawa J (1969) Subtropical mode water. Deep Sea Res 16:463472

Nishikawa S, Kubokawa A (2012) Mixed layer depth front and subduction of low potential vorticity water under seasonal forcings in an idealized OGCM. J Oceanogr 68. doi:10.1007/s10872011-0086-4

Nonaka M, Xie SP, Sasaki H (2012) Interannual variations in low potential vorticity water and the subtropical countercurrent in an eddy-resolving OGCM. J Oceanogr 68. doi:10.1007/s10872-0110042-3
Oka E, Qiu B (2012) Progress of North Pacific mode water research in the past decade. J Oceanogr 68. doi:10.1007/s10872-011-0032-5

Sasaki H, Xie SP, Taguchi B, Nonaka M, Hosoda S, Masumoto Y (2012) Interannual variations of the Hawaiian Lee Countercurrent induced by low potential vorticity water ventilation in the subsurface. J Oceanogr 68. doi:10.1007/s10872-011-0074-8

Toyama K, Suga T (2012) Roles of mode waters in formation and maintenance of Central Water in the North Pacific. J Oceanogr 68. doi:10.1007/s10872-011-0040-5

Uda M, Hasunuma K (1969) The eastward subtropical countercurrent in the western North Pacific Ocean. J Oceanogr Soc Jpn 25:201-210

Xu LX, Xie SP, Liu Q, Kobashi F (2012) Response of the North Pacific Subtropical Countercurrent and its variability to global warming. J Oceanogr 68. doi:10.1007/s10872-011-0031-6

Yoshida K, Kidokoro T (1967) A subtropical countercurrent in the North Pacific - an eastward flow near the Subtropical Convergence. J Oceanogr Soc Jpn 23:88-91 